\title{
Getting to 'know' connectors? Evaluating data-driven learning in a writing skills course
}

\author{
Andy Cresswell \\ University of Bologna
}

\begin{abstract}
This paper sets out to evaluate the effect on learners' knowledge and use of language of one prominent technique in corpus pedagogy, the data-driven use of corpus concordances with learners as researchers, or Data-Driven Learning (DDL) (Johns 1988, 1991). More specifically, the paper attempts measurement of the effect of DDL on the achievement of the goal of appropriate production by learners of logical connectors, an important subskill in the context of the wider objective of the acquisition of basic academic writing skills in English. The evaluation uses learner corpora from experimental and control groups, supported by other methods. The conclusion is that DDL, applied in the context of the communicative teaching of writing skills, is moderately effective, and that there is potential both for the further development of learner corpora in an evaluative role, and for use of a wider range of instrumentation.
\end{abstract}

\section{Introduction}

\subsection{The importance of evaluation of DDL}

Since the arrival of the twenty-first century, there has been a dawning disappointment among some proponents of computer-assisted language learning that there has not been the large-scale adoption of concordancing as a learning tool that the pioneers envisaged (Johns 1986; Leech and Candlin 1986; Johns and King 1991; Hanson-Smith 1993). This is perhaps because the scale of the change envisioned was too grand, too revolutionary. To paraphrase Cobb (1997: 301), what was envisioned was the supplanting of the "process-control" paradigm of instruction associated with the communicative approach, by an information-resource model, in which learners act as researchers and teachers' role is to help them research effectively - i.e. Data-Driven Learning, referred to as DDL (Johns 1986, 1988, 1991). A more dialectical view of paradigm change, as exemplified by Markee (1993), who draws on a solid body of research on the diffusion of innovations across disciplines, would however see the adoption of DDL as a process of integration with the communicative approach. From this viewpoint, the delay in the diffusion of DDL is explained by institutional inertia (Handy 1986), which needs to be confronted with the pro-active use of systematic, critical evaluation (Rogers 1983). In the existing literature on DDL, there are a number of studies establishing the virtue of concordance use in theoretical terms of language and 
learning (e.g. Aston 2001b), but in terms of Roger's (1983) theory on innovation, they tend not to engage sufficiently with the issues of relative advantage, compatibility, trialability and observability, which must be addressed if the sceptical are to be influenced.

This means that evaluation of DDL must move from the theoretical to the practical. For trialability, i.e. establishing how easy DDL is to carry out, we need transparent accounts of the limits of applications of DDL in terms of resources of time, space and money. For compatibility, we need more systematic reports of the contributions concordancing makes to the learning of specific language sets, programme objectives (e.g. reading skill improvement), and approaches (especially communicative language leaching), and the limits of those contributions, including in terms of observed learner behaviour when concordancing. To establish relative advantage in communicative language teaching, we need empirical accounts of learners' contextual use of language items studied through DDL, and comparison with use by learners not using DDL. For observability, we need ways of quantifying any relative advantage, as well as a sufficiently wide range of qualitative instrumentation - this has been rather limited so far, as the next section shows.

\subsection{DDL - Existing evaluation}

There is some existing literature on compatibility, particularly with regard to learner behaviour. Johns has always qualified his advocacy of data-driven learning of lexicogrammar with caveats regarding the tendency of some learners to overgeneralise from single examples (Johns 1988: 25, 1997: 111). Gavioli (2001) deals with such concerns pro-actively, first showing how learners may be daunted by data, then proposing training for DDL on manageable small corpora. In terms of specific language sets, Johns (1988: 23-24) reports that learning about causal markers was credible, usable, attainable and transferable, while Zanettin (2001) worked with the lexis of Olympic competition, reporting on learners finding native-like equivalents. In terms of programme objectives, Johns (1988) reported on compatibility with language-support learners and Zanettin (2001) with learner-translators, while Cheng, Warren and Xun-feng (2003) succeeded in establishing compatibility (within their own institution) through integrating the use of computers in language lessons when the objective was the teaching of information technology. In terms of approaches, Gavioli and Aston (2001) show how "discourse authentication" can make DDL compatible with communicative language teaching. They also observe learners solving problems by applying concordance-derived knowledge, suggesting cognitive validity for DDL, while, on the affective side, Aston (1996), and Cheng, Warren and Xun-feng (2003) have recorded both the acceptability of concordancing to learners and their problems using it. These studies are undoubtedly valuable. However, in each case, the research instruments were either informal observation (Johns 1988; Gavioli 2001; Zanettin 2001), or learner self-report (Aston 1996; Cheng, Warren and Xun-feng 2003); and, while Johns (1988), Aston (1996) and Gavioli (2001) 
provide examples of language reportedly learnt through concordancing, the lack of measured data limits the persuasiveness of the findings in terms of observability, which in turn makes it difficult to judge relative advantage. To enhance observability and establish relative advantage, there would seem to be an urgent need for the gathering of empirical data, while self-reports need to be supplemented by data on compatibility gathered using systematic interview techniques.

In fact, there are some empirical studies. Stevens (1991) showed preintermediate learners recalling words better in gapped concordance lines than in gapped texts, and Cobb (1997: 311) was able to replicate this result using electronic protocols with 100 subjects. The relative advantage showed by Cobb is convincing in observability terms, since there were measurements of performance and a control group, but the study raises issues of trialability, since, to obtain the results, a special programme had to be written, which few have the resources to do. Neither does Cobb address one of the prime compatibility issues, i.e. DDL's integration into the predominant model of language teaching, the communicative approach.

\subsection{DDL in getting to 'know' language}

Cobb's (1997) DDL subjects knew the learnt vocabulary better than his non-DDL subjects. But what do we mean by 'knowing' language? Cobb (1997) appears content to interpret learning in operational terms as transferability. Johns, on the other hand, remarks that being able to transfer a language item in a quiz-like activity is no proof that the item can be produced in 'real' contexts of use (Johns 1988: 10), a viewpoint that reveals the assumptions of the communicative paradigm. Communicative language teaching assumes a distinction between 'declarative' knowledge, roughly definable as abstract formal and contextual awareness, which would enable the learner to recognise the item as a solution in a quiz-like activity, and 'procedural knowledge' (Faerch and Kasper 1984: 215), which permits appropriate use in a "real, live" context.

In this perspective, the role of DDL in knowledge acquisition is to provide examples for "consciousness raising" (Johns 1991: 3) and "hypothesis testing" (Faerch and Kasper 1987: 13). Declarative knowledge, in the form of both more and less generalised schemata of language use (Skehan 1993; Aston 1997: 56), is formed as hypotheses are confirmed against the citations in the database. If a communicative approach to DDL is adopted, then pair or group discussion involving the negotiation between learners of shared meanings in context 'proceduralises' the knowledge, in a process one could paraphrase as "discourse participation through observation" (Gavioli and Aston 2001: 241). I will call this procedure 'communicative DDL' for short. 


\section{$1.4 \quad$ Research aims}

If one applied 'communicative DDL', keeping records of learners' statements of declarative knowledge, one could go on to measure their performance in terms of use of learnt language items in a communicative task, in order to check the extent that learners went beyond declarative knowledge, to actual production. If one used only widely-available retrieval tools, one would ensure trialability. With a non-DDL control group doing the same task, one could write an evaluation of DDL that observed its compatibility with the communicative approach, provided measured data for observability, and was able to come to conclusions about relative advantage.

\section{$1.5 \quad$ Types of DDL}

DDL was initially envisaged by Johns $(1986,1988)$ as a technique for autonomous learning, in which learners formed descriptions of language directly from concordances without the sometimes distorting effect of mediation from resources such as dictionaries and textbooks, and with the teacher's role facilitative rather than directive. This is what I term 'inductive DDL'. In parallel, Johns also advocated less autonomous activities in which learner discovery was directed by teacher-designed exercises (Johns 1994). While recognising that there are inductive as well as deductive processes involved (Aston 2001a: 21), for the sake of simplicity I term this second approach 'deductive DDL'. What I aimed to set up was inductive DDL, though it sometimes became deductive by default, as will be seen.

\subsection{Advanced learners' textual metadiscourse}

The language studied through DDL consisted of a small set of textual metadiscourse items. Textual metadiscourse is used by writers to inform readers of how they expect them to interpret the logical relations between propositions (Vande Kopple 1985). While textual metadiscourse is neither a closed class of items nor restricted to a particular syntactic category (Winter 1977), adverbial connectors are frequently used with this function.1 Because of mother-tongue interference, and their polypragmatic character (Beauvais 1989), connectors are a frequent source of difficulty, even for advanced learners (Granger and Tyson 1996, Altenberg and Tapper 1998). Errors arise because although the learners can generally recognise the forms, they have partial or inaccurate knowledge of the range of meanings and uses associated with them. The connectors chosen for study were generally perceived by myself and colleagues to be particularly problematic for the learners in question, in the ways indicated in Table 1. 
Table 1. Connectors studied

\begin{tabular}{llll}
\hline \multicolumn{1}{c}{ Misused } & \multicolumn{1}{c}{ Over-used } & Underused & $\begin{array}{l}\text { Unproblematic (for } \\
\text { comparison) }\end{array}$ \\
\hline $\begin{array}{lll}\text { instead } \\
\text { in fact }\end{array}$ & $\begin{array}{l}\text { in contrast } \\
\text { anyway }\end{array}$ & $\begin{array}{l}\text { rather } \\
\text { on the other hand }\end{array}$ \\
$\begin{array}{l}\text { as a matter offact } \\
\text { on the contrary }\end{array}$ & as a matter offact & $\begin{array}{l}\text { indeed } \\
\text { yet }\end{array}$ & \\
\hline
\end{tabular}

\subsection{Pedagogic context and procedure}

\subsubsection{Pedagogic context}

The learners were third year undergraduates, of more or less advanced level, studying English Language and Linguistics as part of a degree in Translation or Interpreting. The learning objective was to improve the use of the connectors studied. The course was a module of academic writing, in which students wrote referenced essays from sources, and was taught communicatively, being based on the process-model of writing skills instruction with a three-draft approach including peer evaluation and discussion.

\subsubsection{Pedagogic procedure}

During the course, small groups worked on sub-sets of connectors (Table 1), using Concord (Scott 1999) to make, sort and classify concordances (as in Johns 1991: 4) in corpora of The Independent. Their task was to discover the meanings, uses and syntactic patterns of the connectors. In order to ensure 'discourse participation through observation', learners discussed the citations in groups, before presenting the meanings, patterns and uses of their connectors to the other groups. Provided that they used them to check their own hypotheses rather than substitute for them, learners were allowed to consult reference works. Before beginning, I spoke to the learners in an initial 'training session' about the importance of reflecting on data (Johns 1988: 24). Although I remained available for consultation and advice on researching technique, the final responsibility for the accuracy of the description was the learners'.

\section{$1.8 \quad$ Research questions}

No teacher wants their learners to be led into error, so if one adopted the persona of the sceptical potential adopter of DDL, the most important question would seem to regard the trialability of Johns's claims (1991: 3) about the accuracy of learners' language descriptions: 
One interesting side-effect of the DDL approach seems to be that when grammatical description is the product of the learner's own engagement with the evidence, that description may show a far greater degree of abstraction and subtlety ... than would normally be allowed for in the type of pedagogic description that is 'given'.

So I posed the question:

Q.1 - How effective are learners' own descriptions as metalinguistic communication?

This can be expanded into:

(i) Were descriptions accurate enough to make proceduralisation likely?

and:

(ii) Were descriptions better than those 'given' in reference works?

To establish compatibility with teachers who think according to the process/communicative paradigm, and to take account of concerns of relative advantage, what needs to be established is:

Q.2 - After 'communicative DDL', is there more 'genuine use' of the connectors studied?

\section{Method}

\subsection{Data collection}

The following methods were used to collect data on

(a) metalinguistic ability:

- taping of sample learner presentations;

- documentary evidence: learners' reference material; notes, handouts and transparencies; teacher's notes on presentations;

- informal interviews;

and

(b) 'genuine' use of connectors: 
- learner corpus of essays written by 'DDL learners';

- learner corpus of essays done by 'non-DDL learners', following a writing course the same in all respects other than the absence of the DDL lessons.

Both the DDL and non-DDL corpora consisted of almost exactly 90,000 words, with essays (by 61 and 65 learners respectively) selected through stratified random sampling according to proportions of each of 4 bands of 'pass' essays in each academic year. Concordances of the studied items were made to quantify use.

\subsection{Data analysis}

Recordings and documents were judged for the quality of metalinguistic communication of the meanings and usage of the connectors; "data cooking" (Ulichny 2001), or quantification of grounded qualitative data (Lincoln \& Guba 1985, Strauss 1988, Nunan 1992: 148), was used to evolve appropriate descriptive categories. The originality of descriptions was checked by the researcher through informal interviews after each presentation and comparison against learners' reference sources.

WordList and Concord (Scott 1999) were used to measure relative frequency of acceptable and non-acceptable instances of the DDL-investigated connectors in the DDL and non-DDL learner corpora. The researcher's judgement of acceptable and non-acceptable use of connectors was checked by an independent analyst in a random sample of approximately $15 \%$ of each corpus, resulting in an index of agreement of 0.97 , and the errors were initially identified (and checked) in the original essay scripts, on the principle that a text is only fairly interpreted if "re-materialised" in its original format (Myers 1999: 58).

'More genuine use' of connectors was judged in the following ways:

- appropriate use of a wider variety of (i) different senses, and (ii) different syntactic positions;

- more instances of acceptable use;

- a lower proportion of errors in instances of use.

\section{Results and discussion}

\subsection{Q. 1 - How effective are learners' descriptions as metalinguistic communication?}

Table 2 relates definitions of types of knowledge referred to in this section. These definitions are primarily a heuristic for interpreting the data uncovered in this study and are not proposed as ultimately discrete or watertight. It should be noted that the category 'use' includes both declarative and proceduralised knowledge, as in multi-draft writing language is produced both spontaneously (hence 
procedurally) and through reflection, consultation and revision (i.e. 'declaratively').

Table 2. Knowledge types in DDL

\begin{tabular}{ll}
\hline \multicolumn{1}{c}{ DECLARATIVE } & \multicolumn{1}{c}{ USE } \\
\hline $\begin{array}{l}\text { LINGUISTIC. 'EXPLAINED' } \\
\text { Knowing form, collocations, denotation }\end{array}$ & $\begin{array}{l}\text { PRAGMATIC } \\
\text { Knowing context of use, } \\
\text { connotation }\end{array}$ \\
\hline METALINGUISTIC & $\begin{array}{l}\text { METALINGUISTIC + } \\
\text { Consciously distinguishing forms and }\end{array}$ \\
PRAGMATIC = EXPLICATIVE \\
meir meanings from other forms and & $\begin{array}{l}\text { Able to successfully communicate } \\
\text { meaning in the same semantic or } \\
\text { distinctions of form, meaning, } \\
\text { that a form has different uses }\end{array}$ \\
\hline
\end{tabular}

\subsubsection{Successful inductive descriptions}

8 out of 15 groups of learners presented some inductively derived descriptions (i.e. learners' claims of originality were not invalidated by checks), and which were convincingly accurate, thus showing both declarative knowledge of the item and metalinguistic knowledge in the Use-Pragmatic sense. Descriptions in this category not only constituted evidence of declarative knowledge on the part of the originating learners, but were also clear enough to potentially communicate the meaning to the learners who had not actively investigated that item. This can be seen from Descriptions 1-3, each of which is representative of its 'quality category', and is followed by the corresponding exemplifying citation.

Description 1: original and accurate

Instead introduces the unexpected; it is preceded by what was the common sense expectation.

Citation 1:

The safe option would have been for Carling to run straight, make ground, take the tackle and await the arrival of his supporting forwards. Instead, he unhesitatingly chose the more dangerous but infinitely more rewarding route, to Rory Underwood's wing. (The Independent)

This description is pragmatically accurate, and as abstract and subtle as Johns (1991: 3) claimed learners' descriptions could be. It was also a definition that was absent from any of the students' indicated reference sources, the nearest being the less detailed "a choice or change of behaviour" (Cobuild 2001: 812). 
This example thus confirms Johns's claim that learners' own descriptions can be more accurate than 'given' descriptions.

Description 2 is less original, but nevertheless concentrates on an essential aspect of the semantics of in fact that learners often do not appreciate, i.e. its frequent intensifying, emphatic effect:

Description 2: synthetic and accurate

Restating something mentioned before. Stressing the meaning of the sentence.

Citation 2:

"It was the cleanest game I've ever played against the French", Kenny Milne, the Scottish hooker, said. The game was squeaky clean, too damn quiet in fact. (The Independent)

Description 2 also bears out Johns's claims about descriptive quality. It clearly demonstrates the learners' understanding of the polypragmatic meaning of in fact. To form the same understanding from the reference works, two would have been needed, with emphatic in fact present only in Cambridge (1995: 492), and the restatement use present in the two Cobuilds (1995: 595, 2001: 552).

The third example is one where, to be strictly accurate, I would have preferred a form of words like 'time-finding device':

Description 3: original, accurate, offbeat

As a matter of fact: time-wasting device.

Citation 3:

I thought he was shouting at me like RCA, EMI, the name of a record company. So I took no notice, as a matter of fact. But then, being fazed by reputation is not exactly part of the Presley make-up. (The Independent)

However, the learner's unexpectedly pithy description works pragmatically, in communicating that as a matter of fact is propositionally irrelevant, and reminds us that, when learners' descriptions of language are personalised, they may actually constitute a form of declarative knowledge more susceptible to proceduralisation (Johnson 1994: 125). And again the learners outdid the reference works, in perceiving a strategic use absent in all three.

In sum, the fact that the majority of groups managed to induce descriptions of metalinguistic clarity is evidence that 'communicative DDL' is capable of eliciting declarative knowledge of connectors sufficient to ensure at least potential proceduralisation of these items, while the capacity of learners to form 
descriptions more appropriate than those that are 'given' is further confirmed. At the same time, however, it must be conceded that 6 of the 8 successful inductive groups also included some other descriptions that were less satisfactory, or even misleading, which is a point to which I will return.

\subsubsection{Deductive use of DDL}

The other 7 groups appeared to be uncomfortable with the risk involved in inductive DDL, and preferred to adapt the procedure to work deductivelyinductively, finding different uses in reference works, then working back and forth to find examples in the corpus that corresponded with the reference descriptions. Four 'deductive DDL' groups mostly produced successful descriptions, judged by appropriate matching of descriptions to exemplifying citations. The other groups, however, described the meanings reductively, using general terms taken from reference works. For example, two meanings of on the contrary are distinguished, more or less accurately, as 'reinforcing' (description/citation 4) and 'contrastive' (description/citation 5).

Description 4: reductive

Reinforcing.

Citation 4:

Britain is a European country with many problems that demand European solutions. Failure to ratify the treaty will not make these problems go away. On the contrary, it will make them very much worse, and remove from this and future British governments any influence over the solutions eventually decided upon. (The Independent)

Description 5: reductive

Contrastive.

Citation 5:

It might have seemed for a moment, as law and order dissolved there, that George Bush's chances of re-election were seriously damaged. On the contrary, though Mr Bush is clearly personally shocked by the acquittal of the four policemen who beat Rodney King, on balance his electoral prospects are much enhanced. (The Independent)

In selecting useful key words to distinguish two pragmatic effects of on the contrary, these learners have arguably arrived at declarative knowledge of the 
item. However, their thinking is not metalinguistic, in the sense of consciously distinguishing forms and meanings from other forms and meanings, as in description 6, they also describe on the other hand as 'contrastive'.

Description 6: reductive

Contrastive.

Citation 6:

Third World nations also want a new "Green Fund" set up under their control, to channel the aid to their countries. Mr Strong, on the other hand, has said that the aid should go to a variety of agencies, especially the World Bank. (The Independent)

This 'distinguishing' contrastive use clearly differs from the 'contrastive' use of on the contrary, which contradicts a reported or hypothesised proposition, showing how descriptions 5 and 6 are conflated. They display what is called 'explained' declarative knowledge, which is a rudimentary schema sufficient for the individual learner to more or less cope. This contrasts with 'explicative' declarative knowledge, which is the non-native's accurate account of the situational and cotextual associations which for a native speaker are implicit (Levelt 1978: 5, James 1994: 209). The presence of 'explained' descriptions in 'deductive' groups, and the contrasting presence of 'explicative' descriptions in 'inductive' groups, may be accounted for by the theory of learner types (Kolb 1984, Skehan 1998). 'Deductive' groups may have found approximate accommodation of the form-meaning correlation a more comfortable route to eventual proceduralisation (Johnson 1994: 125) as a result of being fielddependent 'holists' who prefer to accommodate rather than analyse. These learners may simply have preferred not to invest in the analytical aspects of meaning definition, which did not suit their learning style. Contrariwise, the 'inductive' groups may have been field-independent 'analysts' who were happy examining citations and developing abstract and explicative descriptions.

Yet the same characteristic of failing to describe forms and meanings adequately enough to avoid confusion with related but distinct forms and meanings can be observed in the account of on the contrary in description 7 , which was supplied by an 'inductive group' who otherwise gave correct definitions.

Description 7: original but misleading

$\ldots$ it is interesting to notice that any sentence containing on the contrary never implies the falseness of the preceding sentence. That is, both statements ... are true. 


\section{Citation 7:}

It is greatly to his credit that he never blocked major administrative reforms advocated by his subordinates. On the contrary, he championed them once he had accepted proposals as sound. (The Independent)

Interestingly, the apparently inaccurate remark "never implies the falseness of the previous sentence" actually implies a metalinguistic appreciation of a characteristic of a number of instances of on the contrary, which Cobuild (2001: 328) restricts to quite the contrary, but which is accurately described as "emphasis[ing] a previous negative statement".

Appropriate qualification, like "this class of examples of on the contrary preceded by a negative statement never implies the falseness of the previous sentence", would have resulted in a clear, useful distinction; but the student's description implies she is talking about all instances of on the contrary. In effect, this creates confusion, particularly since a subsequent example from the same group actually does imply the falseness of a statement reported in the previous sentence:

Citation 8:

Mr Ashdown told delegates we are told that ours is a wasted vote. On the contrary. Ours will be the most valuable vote of them all. (The Independent)

Descriptions 5 and 6 (from deductive DDL), as explained knowledge, are clearly insufficient as schemata to prevent erroneous confusion in use of on the other hand and on the contrary. Description 7 (from inductive DDL) is a clear attempt at explicative knowledge, but it, too, fails to achieve the avoidance of ambiguity that would facilitate proceduralisation and accurate use.

The emergence of less successful descriptions indicates claims of the efficacy of DDL should be qualified - after all, inadequate descriptions may give rise to wrong schemata, leading to fossilisation (Johnson 1994: 123). Yet the 'explained' descriptions which were more typical of the deductive groups did reflect declarative knowledge, potentially providing the base for future proceduralisation while being too ambiguous to themselves constitute evidence of it. Ambiguous explicative description (as exemplified by description 7) among the 'inductive' groups could also indicate potential proceduralisation, being an example of "proximal development" (Vygotsky 1978: 86), a stage of imprecise knowledge obtained from peer collaboration, constituting a signal for teacher intervention to complete development. And, once the qualifications are made, it should be asserted that the majority of the descriptions were successful, with 12 out of the 15 groups producing descriptions that were mostly accurate, and did not contain ambiguities. Add to this that among the 'inductive' groups, descriptions were sometimes impressive (e.g. Description 1), and one can 
conclude, on balance, that although only some learners form descriptions at the high levels of accuracy and abstraction posited by Johns (1991: 3), given the variety of learning preferences predicated by learning styles, this is already something; while most learners seem to have obtained a level of knowledge where proceduralisation of the language is at least possible. So we can now turn to the second question.

\subsection{Q. 2 - After 'communicative DDL', is there more 'genuine use' of the connectors studied? Learner corpus results}

The learner corpus data, since they are based on a 'genuine' productive task, reveal knowledge of use of the connectors in the DDL and non-DDL corpora. The first two tests applied were concordances of each connector, classified first according to variety of syntactic position, and second, by the number of different uses. In neither case was there any striking difference between results in the two corpora (despite the fact that learners had accurately noted the variety of positions in their presentations). Tables 3 and 4 illustrate this finding for the connector in fact.

Table 3. In fact: syntactic positions

\begin{tabular}{lcc}
\hline \multicolumn{1}{c}{$\begin{array}{c}\text { IN FACT } \\
\text { (connector uses only) }\end{array}$} & $\begin{array}{c}\text { DDL } \\
\text { CORPUS }\end{array}$ & $\begin{array}{c}\text { NON-DDL } \\
\text { CORPUS }\end{array}$ \\
\hline $\begin{array}{l}\text { No. OF DIFFERENT POSITIONS } \\
(\mathrm{t}=\text { total tokens) }\end{array}$ & 5 & 4 \\
\hline POSITIONS IDENTIFIED: & $(\mathrm{t}=44)$ & $(\mathrm{t}=36)$ \\
$1-$ after an adverbial & & \\
$2-$ initial in clause or after and & & \\
$3-$ end of clause, as adverbial complement & & \\
$4-$ after subject & & \\
$5-$ after verb & & \\
\hline
\end{tabular}

Table 4. In fact: semantic uses

\begin{tabular}{lcc}
\hline \multicolumn{1}{c}{$\begin{array}{c}\text { IN FACT } \\
\text { (connector uses only) }\end{array}$} & $\begin{array}{c}\text { DDL } \\
\text { CORPUS }\end{array}$ & $\begin{array}{c}\text { NON-DDL } \\
\text { CORPUS }\end{array}$ \\
\hline $\begin{array}{l}\text { No. OF DIFFERENT POSITIONS } \\
(\mathrm{t}=\text { total tokens) }\end{array}$ & $\begin{array}{c}4 \\
(\mathrm{t}=44)\end{array}$ & $(\mathrm{t}=36)$ \\
\hline SEMANTIC USES CLASSIFIED: & & \\
$1-$ introducing further details & & \\
$2-$ contrastive/corrective & & \\
$3-$ presenting proof & & \\
$4-$ in reality & & \\
\hline
\end{tabular}


The apparent lack of effect of DDL on learners' use of in fact in different syntactic positions (Table 3) might indicate that knowledge of variable positioning is best obtained procedurally, through reading and writing of entire texts, to give more discourse context. The conscious declarative focus potentiated by DDL is thus perhaps irrelevant in the case of acquisition of syntactic positioning. The lack of difference in variety of semantic uses between the DDL and non-DDL corpora similarly suggests that the uses were chosen in response to the demands of the common writing task. So a DDL effect on variety of semantic uses is ruled out.

In the third test, concordances of the problematic connectors (Table 1) were compared with the original corrected essay scripts to obtain percentages of correct use. This revealed a slight advantage in correctness in the DDL corpus in 2 out of 10 cases (Table 5), with the rest showing no or hardly any difference.

Table 5. Connectors: fewer errors with DDL (non-connector tokens excluded)

\begin{tabular}{ccc}
\hline Connectors & $\begin{array}{c}\text { DDL } \\
\text { \% correct tokens }\end{array}$ & $\begin{array}{c}\text { NON-DDL } \\
\text { \% correct tokens }\end{array}$ \\
\hline in fact & 75 & 63 \\
\hline indeed & 97 & 88 \\
\hline
\end{tabular}

In the fourth test, regarding frequency of correct use, it turned out that two connectors were used more in the DDL than in the non-DDL corpus (Table 6).

Table 6. Connectors: frequency of use

\begin{tabular}{ccc}
\hline More use in DDL & $\begin{array}{c}\text { DDL } \\
\text { correct / total }\end{array}$ & $\begin{array}{c}\text { NON-DDL } \\
\text { correct / total }\end{array}$ \\
\hline in contrast (to + NP) & $10 / 10$ & $3 / 3$ \\
\hline yet & $18 / 18$ & $14 / 14$ \\
\hline
\end{tabular}

In synthesis, for most of the connectors, DDL had little or no observable effect on quantity and variety of use, perhaps because of the overriding effect on acquisition of the task, or because the items were not at a suitable level for acquisition. Alternatively, given that it seems a time lapse is necessary for input to become output (Bialystok 1978: 4), it may be that completion of the writing task followed too closely on the DDL project. On the other hand, arguing for a DDL effect, among the DDL learners there was slightly more accurate use of indeed and in fact (Table 5), and, in more pronounced fashion, more use of in contrast (Table 6). Overall, given that the students were advanced and the items already partially known, it is possible to conclude, albeit tentatively, that, given language items at the right level, DDL has an observable (though slight) positive effect on actual use. 


\subsection{How widespread was the DDL effect?}

When I applied a fifth test, of the numbers of students using each connector correctly, there was one of two results. Either, (i) there was no or hardly any difference in number of users between the DDL and non-DDL corpora, or (ii) the number of correct users was higher in the non-DDL corpus, even though the number of correct tokens was roughly the same in both corpora (Table 7). This seems to indicate that the DDL effect on use manifested itself largely in certain individuals who used certain connectors more, rather than on increasing knowledge of use in the students as a whole.

Table 7. No. of learners correctly using each connector

\begin{tabular}{|c|c|c|}
\hline Connector & $\begin{array}{l}\text { DDL learners, } \mathrm{n} \\
\quad(\text { correct tokens, } \mathrm{n})\end{array}$ & $\begin{array}{l}\text { non-DDL learners, } \mathrm{n} \\
\text { (correct tokens, } \mathrm{n})\end{array}$ \\
\hline anyway & (0) & $(0)$ \\
\hline as a matter of fact & (1) & $(0)$ \\
\hline indeed & 12 & 20 \\
\hline in fact & (44) & (36) \\
\hline instead & (4) & (6) \\
\hline in contrast & $(10)$ & (3) \\
\hline nevertheless & (14) & 19 \\
\hline on the contrary & (10) & (10) \\
\hline on the other hand & (63) & 36 \\
\hline yet & 11 & 10 \\
\hline
\end{tabular}

This raises the question of which students used connectors better after the DDL projects and which did not. The less than ideal quality of communication in the presentations suggested examining whether, among 'DDL learners', those who investigated an item were more likely to use it correctly than those who merely listened to the description of the item's use. To investigate this, I looked at concordances of those items that seemed from the error correction to be most problematic (Table 8). 
Table 8. Error avoidance in DDL learners

\begin{tabular}{ccc}
\hline Connector & $\begin{array}{c}\text { Investigators } \\
\text { making errors (total) }\end{array}$ & $\begin{array}{c}\text { Non-investigators } \\
\text { making errors (total) }\end{array}$ \\
\hline instead & $1(5)$ & $3(3)$ \\
\hline as a matter of fact & $0(1)$ & $6(6)$ \\
\hline in fact & $2(4)$ & $13(13)$ \\
\hline
\end{tabular}

These figures suggest some influence of participation in data-driven investigation of a problematic item in the reduction of errors in its use, though it also seems possible from the lower number of users of some items (Table 7) that this came about partly through learners avoiding an item rather than using it correctly. This is not necessarily to be regretted, as in the case of as a matter of fact, where the standard error consisted in misleadingly inserting it in places where no connector was needed. In avoiding this item in their argumentative academic essays, the investigators were applying DDL-derived understanding that its use was restricted principally to narrative contexts. One can account for this in terms of 'un-proceduralisation', the process by which, through the critical examination of examples, false hypotheses on use are rejected, and new, more accurate declarative knowledge takes the place of false procedural knowledge (Johnson 1994: 124). It is probably the case that the 'negative reinforcement' that determines the un-proceduralisation induces an inordinate sense of caution, which takes a certain time to wear off before 're-proceduralisation' ensues, in the form of correct situational use. In sum, this should caution us that the conclusions learners arrive at through the study of multiple examples in concordances have effects on use that vary to include inhibiting as well as encouraging effects (albeit the former are temporary).

The converse point is that, for problematic items, non-investigators are more likely to make errors, even if they have heard investigators' descriptions. Thus 'heard' data-driven information is unable to achieve the same proceduralising effect on use of an item as active investigation with its 'discourse participation'.

\section{Conclusions}

\subsection{Compatibility and relative advantage: pedagogical considerations}

In terms of compatibility, for most learners, Johns's $(1991: 3,12)$ existing claims about the efficacy of language description are borne out, in terms of the formation of 'metalinguistic' declarative knowledge, with varying degrees of accuracy of description. This variation is hypothesised as due to learning style differences - a hypothesis that needs further testing. The relative advantage of 'communicative DDL' on production is shown, to a limited extent, in the transfer of declarative knowledge obtained from DDL to knowledge measurable in terms of number of 
occasions of use, for some of the connectors, and the enhanced ability to avoid error of investigators over non-investigators. However, the fact that there was no DDL effect of greater variety of use of syntactic positions seems to imply that extensive processes of reading and writing are paramount in this respect, rather than the conscious declarative focus of DDL. The finding that there was no DDL effect on greater variety of semantic applications is explicable in terms of being the result of engagement with the task, but is contradictory of the positive results obtained in the other tests. More research is needed to clarify this contradiction.

The confirmation of the validity of learners' DDL-derived descriptions should be qualified, since many learners had not developed the explicative metalinguistic dimension necessary to transmit the understanding. While learners' descriptions can be accurate and insightful, they are not reliable enough (even in advanced learners) to ensure that essential distinctions of meaning and use are communicated to peers. The implications of this for compatibility with communicative language teaching are that, while group-based 'discourse participation through observation' benefits the participating individuals, the sharing of group findings in plenary session, a common communicative procedure, is unlikely to have positive proceduralising effects, and thus demands teacher vigilance to prevent misleading information possibly leading to fossilisation.

Compatibility of DDL to learner types is another important pedagogical consideration. The fact that, despite being encouraged to produce language descriptions inductively, some learners were able to work only by adapting the activity to a more deductive approach, implies that instructors intending students to work as learner-researchers should consider the needs of holist learners for support from reference materials. This does not necessarily impinge on the efficacy of DDL as a learning method. Learning styles are probably dynamic rather than fixed (Kolb 1984), and 'deductive DDL' can in this perspective be seen as a stage on the way to the more effective 'inductive DDL'. It would be interesting to conduct a longitudinal study to verify this.

\subsection{Trialability and observability: reflections on evaluating DDL}

First, there are considerations relating to the combination of retrieval tools and learner corpora in evaluation of DDL. The use of WordSmith (Scott 1999) permitted an evaluation with a fairly high degree of observability, since frequency could be measured and empirical results obtained, as well as a high degree of trialability as the programme is widely available. However, there are limits in this study that indicate that there is room for further improvement of the accuracy of learner corpora as an instrument for evaluating DD. For a start, results would be more convincing if corpora were balanced, not just in proportion to learners' ability bands as in the current study, but also in proportion to the numbers investigating each sub-set of language items. Additionally, in order to make the context of observed use more likely to correspond to the context of productive use, it would be worth undertaking research with a study in which learners 
studied using a corpus generically closer to their productive task, rather than a newspaper corpus. Overall, though, the use of retrieval tools on learner corpora permitted accurate measurement of the effect of DDL in a communicative written task, permitting claims about the effect of DDL on language use of items used in that task. This suggests the retrieval tool-learner corpora combination could be further exploited in the evaluation of DDL's compatibility with the dominant process-communicative teaching paradigm if it was applied to a variety of sets of investigated language items similarly co-ordinated with communicative writing tasks in which they are likely to be needed.

Second, observability also needs to be improved by adopting a wider range of instrumentation, to supplement the empirical evidence gathered from a learner corpus with systematic accounts of how individuals act during the smallgroup discussion-of-citations-and-descriptions stage. Discourse-based interviews (Odell, Goswami and Herrington 1983) about subjects' motivations in language choice might reveal enhancing or inhibiting effects on use of declarative knowledge obtained from DDL. Additionally, the use of video-recorded protocols (Sealey and Thompson 2004) could permit the identification of more inductive or deductive approaches in individual learners, permitting the comparison of learner profiles with extent and variety of use of studied language in the learner corpus. These methods could permit description of the different effects of DDL on holist and analytic learners, and provide a detailed explanation for why inductive DDL appears to work better for some individuals than for others.

\section{Notes}

1 Terminology and syntactic classification are heterogeneous. Textual metadiscourse 'adverbials' are variously called 'conjunctive adjuncts' (Halliday and Hasan 1976: 231), 'conjunctions' (Martin 1992: 178), 'subjuncts', 'disjuncts', 'conjuncts' and 'adjuncts' (Quirk et al. 1985: 52).

\section{Learners' reference works}

Cambridge (1995), Cambridge international dictionary of English. Cambridge: Cambridge University Press.

Cobuild (1995), Collins COBUILD English dictionary. London: HarperCollins.

Cobuild (2001), Collins COBUILD English dictionary for advanced learners. London: HarperCollins.

\section{References}

Altenberg, B. and M. Tapper (1998), 'The use of adverbial connectors in advanced Swedish learners' written English', in: S. Granger (ed.), Learner English on computer. London: Longman, 80-93. 
Aston, G. (1996), 'The British National Corpus as a language learner's resource', in: S. Botley, J. Glass, T. McEnery and A. Wilson (eds.), Proceedings of teaching and language corpora. Lancaster: UCREL, 178-191.

Aston, G. (1997). 'Enriching the learning environment: corpora in ELT', in: A. Wichmann et al. (eds.), 51-64.

Aston, G. (2001a), 'Learning with corpora: an overview', in: G. Aston (ed.). 745.

Aston, G. (ed.) (2001b), Learning with corpora. Bologna: CLUEB.

Beauvais, P. (1989), 'A speech-act theory of metadiscourse', Written Communication, 6/1: 11-30.

Bialystok, E. (1978), 'A theoretical model of second language learning', Language Learning, 28: 69-84.

Bygate, M., A. Tonkyn and E. Williams (eds.) (1994), Grammar and the language teacher. Hamel Hampstead: Prentice Hall.

Cheng, W., M. Warren and Xu Xun-feng (2003), 'The language learner as language researcher: putting corpus linguistics on the timetable', System, 31: 173-186.

Cobb, T. (1997), 'Is there any measurable learning from hands-on concordancing?', System, 25: 301-315.

Faerch, C. and G. Kasper (1984), 'Pragmatic knowledge: rules and procedures', Applied Linguistics, 5: 214-225.

Faerch, C. and G. Kasper (1987), 'Procedural knowledge as a component of foreign language learners' communicative competence', in: T. SlamaCazacu (ed.), Psycholinguistcs: AILA Review 1986, 3: 7-23, originally published in H. Bolte and W. Herrlitz (eds.) (1985), Kommunikation im Sprachunterricht. Utrecht: University of Utrecht, 169-200.

Gavioli, L. (2001), 'The learner as researcher: introducing corpus concordancing in the classroom', in: G. Aston (ed.), 108-137.

Gavioli, L. and G. Aston (2001), 'Enriching reality: language corpora in language pedagogy', English Language Teaching Journal, 55/3: 238-246.

Granger, S. and S. Tyson (1996), 'Connector usage in the English essay writing of native and non-native EFL speakers of English', World Englishes, 15/1: 17-27.

Halliday, M.A.K. and R. Hasan (1976), Cohesion in English. London: Arnold.

Handy, C. (1986), Understanding schools as organisations. Harmondsworth: Penguin.

Hanson-Smith, E. (1993), 'Dancing with concordances', CAELL Journal, 4/2: 40.

James, C. (1994), 'Explaining grammar to its learners', in: M. Bygate, A. Tonkyn and E. Williams (eds.), 203-214.

Johns, T. (1986), 'Micro-concord: a language learner's research tool', System, 14/2: 151-162.

Johns, T. (1988), 'Whence and whither classroom concordancing?', in: T. Bongaerts, P. de Haan, S. Lobbe and H. Wekker (eds.), Computer applications in language learning. Dordrecht: Foris, 9-33. 
Johns, T. (1991), 'Should you be persuaded - two samples of data-driven learning materials', in: T. Johns and P. King (eds.), 1-16.

Johns, T. (1994), 'From printout to handout: grammar and vocabulary teaching in the context of Data-Driven Learning', in: T. Odlin (ed.), Perspectives on pedagogical grammar. Cambridge: Cambridge University Press, 293-313.

Johns, T. (1997), 'Contexts: the background, development and trialling of a concordance-based CALL program', in: A. Wichmann et al. (eds.), 110115 .

Johns, T. and P. King (eds.) (1991), Classroom concordancing: ELR Journal, 4. University of Birmingham: Centre for English Language Studies.

Johnson, K. (1994), 'Teaching declarative and procedural knowledge', in: M. Bygate, A. Tonkyn and E. Williams (eds.), 121-131.

Kolb, D.A. (1984), Experiential learning. Englewood Cliffs, N.J.: Prentice Hall.

Leech, G. and C. Candlin (1986), Computers in English language teaching and research. London: Longman.

Levelt, W., A. Sinclair and R. Jarvella (1978), 'Causes and functions of linguistic awareness in language acquisition: some introductory remarks', in A. Sinclair, R. Jarvella and W. Levelt (eds.), The child's conception of language. Berlin: Springer, 1-14.

Lincoln, Y.S. and E.G. Guba (1985), Naturalistic inquiry. Newbury Park, Calif.: Sage Publications.

Martin, J. (1992), English text: system and structure. Amsterdam: Benjamins.

Myers, G. (1999), 'Interaction in writing: principles and problems', in: C. Candlin and $\mathrm{K}$. Hyland (eds.), Writing: texts, processes and practice. London: Longman, 40-61.

Nunan, D. (1992), Research methods in language teaching. Cambridge: Cambridge University Press.

Odell, L., D. Goswami and A. Herrington (1983), 'The discourse-based interview: a procedure for exploring the tacit knowledge of writers in nonacademic settings', in: P. Mosenthal, L. Tamor and S.A. Walmsley (eds.), Research on writing: principles and methods. New York: Longman. 221236

Quirk, R., S. Greenbaum, G. Leech and J. Svartvik (1985), A comprehensive grammar of the English language. London: Longman.

Rogers, E. (1983), Diffusion of innovations. New York: Collier-Macmillan.

Scott, M. (1999), Wordsmith Tools 3.0. Oxford: Oxford University Press.

Sealey, A. and P. Thompson (2004), 'Kids, corpora and concordancing', paper presented at the Sixth Teaching and Language Corpora Conference, Granada, Spain, 6-9 July 2004.

Skehan, P. (1998), A cognitive approach to language learning. Oxford: Oxford University Press.

Stevens, V. (1991), 'Concordance-based vocabulary exercises: a viable alternative to gap-fillers', in: T. Johns and P. King (eds.), 47-62. 
Ulichny, P. (2001), 'HyperResearch software applied to the analysis of text data', presentation made at the conference on Language and identity: software for qualitative research on linguistic data, Bologna, Italy, 30 June 2000.

Vande Kopple, W. (1985), 'Some exploratory discourse on metadiscourse', College Composition and Communication, 36: 82-93.

Vygotsky, L. (1987), Mind in society: the development of higher psychological processes. Cambridge, MA.: Harvard University Press.

Wichmann, A., S. Fligelstone, T. McEnery and G. Knowles (eds.) (1997), Teaching and language corpora. London: Longman.

Winter, E. (1977), 'A clause-relational approach to English texts: a study of some predictive items in written discourse', Instructional Science, 6/1: 1-92. 